\section{Professional Development, Shifting Perspectives, and Instructional Change among Community College Anatomy and Physiology Instructors}

\author{
Audrey Rose Hyson, ${ }^{*}$ Branden Bonham, ${ }^{*}$ Suzanne Hood, $\$$ Megan C. Deutschman, \\ Laura C. Seithers," Kerry Hull," and Murray Jensen" \\ ${ }^{\dagger}$ College of Biological Sciences, "Organizational Leadership, Policy \& Development, and \\ 'College of Biological Sciences, University of Minnesota, Minneapolis, MN 55455; 'Biology \\ Department, Bishop's University and 'Psychology Department, Bishop's University, Sherbrooke, \\ Quebec J1M1Z7, Canada
}

\begin{abstract}
This paper presents community college (CC) instructors' responses to the Community College Anatomy and Physiology Educational Research (CAPER) project, a professional development program focused on active learning and educational research. We engage with conceptual change theory to better understand why and how CC instructors shifted their perspectives toward active learning. Qualitative data indicate that the participating CC instructors experienced pedagogical discontentment, leading to increased positive beliefs about active learning and educational research. In addition, we find that CC instructors have continued their pursuit of pedagogical change and educational research through communities of practice, which provide positive learning environments.
\end{abstract}

\section{INTRODUCTION}

Community colleges (CCs) play an important role in higher education in the United States, serving $37 \%$ of all undergraduates, including $50 \%$ of all Latinx and Indigenous students and $40 \%$ of all Black and Asian students (Twombly and Townsend, 2008). Approximately $50 \%$ of students earning undergraduate degrees began their studies at a CC (Flynn et al., 2017). Teaching a large and diverse population of students, CC faculty comprise $43 \%$ of all public, nonprofit higher education instructors (Twombly and Townsend, 2008). Roughly two-thirds of these faculty are part-time and teach about one-third of the total classes, meaning that the full-time faculty are carrying about two-thirds of the classes and teach approximately five 3-hour classes per week (Twombly and Townsend, 2008; Parker et al., 2016).

\section{Professional Development}

While CCs are teaching-focused institutions, CC faculty are often hired based on their research experience rather than their teaching experience (Edwards et al., 2015; Flynn et al., 2017). Despite their roles as educators, many CC instructors have limited access to professional development (PD) opportunities to support their development of pedagogical expertise (Edwards et al., 2015; Parker et al., 2016; Flynn et al., 2017). Science, technology, engineering, and math (STEM) higher education faculty with varying levels of teaching experience often model their teaching practices on how they were taught or their individual classroom experiences (Hardre, 2012; Oleson and Hora, 2014; Seithers et al., 2020). Furthermore, pedagogical knowledge gained from PD programming does not always result in altered classroom practices (Woodbury and Gess-Newsome, 2002). In their study of undergraduate biology instructors, Andrews and Lemons (2015) found that factors such as personal experiences, observations of
Tessa C. Andrews, Monitoring Editor Submitted Feb 12, 2021; Revised Jun 28, 2021; Accepted Jun 30, 2021

CBE Life Sci Educ September 1, 2021 20:ar49 DOI:10.1187/cbe.21-02-0037

*Address correspondence to: Audrey Rose Hyson (hyson003@umn.edu).

(c) 2021 A. R. Hyson et al. CBE-Life Sciences Education @ 2021 The American Society for Cell Biology. This article is distributed by The American Society for Cell Biology under license from the author(s). It is available to the public under an Attribution-Noncommercial-Share Alike 3.0 Unported Creative Commons License (http://creativecommons.org/licenses/ by-nc-sa/3.0).

"ASCB®" and "The American Society for Cell Biology $\otimes^{\circ}$ are registered trademarks of The American Society for Cell Biology. 
student outcomes, supportive colleagues, and administration either encourage or discourage the incorporation of active-learning techniques. Although CC faculty and researchers have documented a strong need for support around pedagogy, heavy teaching loads limit time for attending PD workshops, changing classroom practices, or conducting educational research (Edwards et al., 2015). While faculty tend to benefit most from a PD system of continuous learning and support, opportunities often come in the form of one-time workshops that do not provide enough contact for sustained instructional improvement (Edwards et al., 2015). Therefore, while research indicates that CC instructors would benefit most from long-term PD programming in supportive CC environments, many factors within their teaching and learning environments tend to impede this type of professional growth.

Engagement in educational research may address many of the factors identified by Andrews and Lemons (2015), such as fostering observations of student outcomes and appealing to CC instructors' research identity. Indeed, Hardre (2012) found that CC faculty are more likely to conduct educational classroom research on methods of teaching and learning than to engage in applied research on topics other than education or in PD programming. Schinske et al. (2017) identified four characteristics that might facilitate biology educational research at CCs-a diverse student population, a culture of assessment, a workforce-preparation orientation, and a focus on pedagogy. These factors come together to provide a rich environment for researching STEM education for traditionally underserved students to improve student performance and incorporate innovative teaching methods to develop skills for the workplace (Schinske et al., 2017).

However, the previously mentioned barriers to CC instructor PD similarly apply to conducting educational research. Their heavy teaching loads mean that CC faculty are not provided with enough time to learn about or conduct CC educational research (Schinske et al., 2017). They also have limited access to the tools, funding, journals, and institutional review board (IRB) research clearance necessary to conduct and publish research (Schinske et al., 2017). As research is not an expectation for CC faculty, they may lack support or even face suspicion from peers and administrators who may question the purposes of their research (Schinske et al., 2017). Finally, unlike many traditional 4-year colleges and universities where publications are necessary for job promotion, there are few formal incentives or rewards for CC faculty to publish educational research, leading to a misalignment between their professional and research identities (Schinske et al., 2017). To that end, this study seeks to understand how a long-term PD program integrating pedagogical training with research opportunities impacts CC instructors' teaching practices. The following questions are used to frame this research: How, if at all, did participants in the Community College Anatomy and Physiology Education Research (CAPER) project demonstrate a change in beliefs or attitudes regarding their teaching practice? How, if at all, did participants in the CAPER program enact changes in pedagogy to incorporate active learning into their classrooms?

\section{The CAPER Project}

The CAPER project included both longer-term PD and training in educational research for CC instructors while simultaneously
TABLE 1. Participants.

\begin{tabular}{|c|c|c|}
\hline & Professor & Educational background \\
\hline \multirow[t]{6}{*}{ Year 1} & Garcia & MS in biology \\
\hline & Tilak & $\mathrm{PhD}$ in molecular biology \\
\hline & N. Klein & $\mathrm{PhD}$ in biological anthropology \\
\hline & Vogelsang & MS evolutionary biology \\
\hline & Dugan & $\mathrm{PhD}$ \\
\hline & Tracy & $\mathrm{PhD}$ in anatomy and cell biology \\
\hline \multirow[t]{6}{*}{ Year 2} & Griffin & $\mathrm{PhD}$ in biology \\
\hline & Blewett & $\begin{array}{l}\text { MS biomedical sciences; PhD candidate clinical } \\
\text { psychology }\end{array}$ \\
\hline & Plum & Master's in public health; DVM \\
\hline & Tabard & $\mathrm{PhD}$ in physiology \\
\hline & Fleur & $\mathrm{PhD}$ in molecular and cellular biology \\
\hline & Jones & MS in physiology \\
\hline
\end{tabular}

studying the CC instructors' pedagogical change. The CAPER project was based on the premise that involvement in educational research could effectively promote pedagogical transformation in CC instructors. The CAPER project did not, however, remove any time constraints or mitigate any institutional characteristics that are often seen as barriers to PD. This National Science Foundation (NSF)-funded project (award no. 1829157, 2018-2020) engaged two cohorts of six CC instructors each (see Table 1). Note that all of the names that appear in Table 1 are pseudonyms.

First, the 12 participating CC anatomy and physiology instructors took a Human Anatomy and Physiology Society Institute (HAPS-I) course about active-learning techniques and educational research. During this course, the CC instructors investigated a variety of pedagogical techniques, including clicker questions, self-reflection exercises (e.g., muddiest point), and group quizzing, that have been shown to promote active learning. They each chose one technique to implement in their classrooms that was then the focus of an educational research project. By the end of the course, each CC instructor had developed a research project proposal with feedback from colleagues, mentors, and the CAPER team. Then, the CC instructors conducted classroom research with support from their mentors in which they integrated one active-learning technique into their teaching and analyzed student responses to it. While CC instructors were collecting data from their research, the CAPER project team collected both quantitative and qualitative data from the CC instructors on their teaching. This article focuses on the data that the CAPER project team collected on instructors' beliefs and practices over time during their participation in the CAPER project.

\section{Theoretical Framework: Pedagogical Discontentment as a Catalyst for Change}

Conceptual Change Theory Several scholars of PD in STEM, including Gess-Newsome et al. (2003), Olitsky (2015), Southerland et al. (2011), and Woodbury and Gess-Newsome (2002), use the concepts of cognitive dissonance, pedagogical discontentment, or pedagogical dissatisfaction and self-efficacy in combination to study how educators move toward or away from pedagogical change. Researchers define the terms "cognitive dissonance," "pedagogical discontentment," and "pedagogical 
dissatisfaction" slightly differently. Olitsky (2015), however, states their similarities clearly, "While these terms vary somewhat in their meaning and use, at a general level, they imply a process by which teachers come to view their current practices as inadequate through some type of dissonance-inducing experience" (Olitsky, 2015, p. 626).

These concepts stem from conceptual change theory, an area of scholarship that seeks to understand how students rely on, replace, and reorganize previously developed concepts to investigate and accommodate new concepts (Posner et al., 1982). Accommodation commonly occurs when a student is dissatisfied with existing conceptions and is able to grasp a new conception that is intelligible, plausible, and has the potential to extend to new areas of inquiry (Posner et al., 1982). This theory has been adapted to consider why and how science instructors learn about new ways of teaching and enact pedagogical changes (Feldman, 2000; Gess-Newsome et al., 2003; Southerland et al., 2011).

This article draws on many conceptual elements derived from the theory of conceptual change to explain why and how CC instructors accommodate, assimilate, or reject active-learning techniques. We pay particular attention to pedagogical discontentment, as all participants discussed experiencing such discontentment during CAPER and responded with varying levels of change in attitude toward active learning. Pedagogical discontentment can be understood as the "state of cognitive conflict that exists when an individual recognizes a mismatch between her/his science teaching pedagogical goals and classroom practices" (Southerland et al., 2011, p. 299). The pedagogical discontentment framework explains a process in which instructors perceive a discrepancy between their ideas of good teaching and their perceptions of their teaching. Instructors' recognition of this gap acts as a catalyst for seeking out new teaching methods and changing instructional practices to reduce discrepancies (Gess-Newsome et al., 2003; Southerland et al., 2011; Olitsky, 2015).

However, depending on their self-efficacy, educators may respond to pedagogical discontentment by either moving toward change or engaging in avoidance behaviors (Gess-Newsome et al., 2003; Southerland et al., 2011; Olitsky, 2015). Therefore, when considering pedagogical discontentment, it is important to consider the role of self-efficacy. According to Southerland et al. (2011), "Self-efficacy is the forecast about one's potential capacity to be successful in a future situation" (p. 305). In other words, self-efficacy can be understood as instructors' belief that they are capable of using new teaching methods effectively. Self-efficacy is often discussed as working in concert with pedagogical discontentment; however, the "level" or "amount" of self-efficacy that is needed for an instructor to enact changes is still debated (Gess-Newsome et al., 2003; Southerland et al., 2011; Saka and Keklikci, 2019). Therefore, PD instructors must walk the line between fostering self-efficacy and maintaining a certain degree of pedagogical discontentment so that teachers feel confident enough in their skills to implement reforms, but not so confident that they see their own teaching as perfect (Southerland et al., 2011; Olitsky, 2015).

Systemic Evaluation of Change. The teacher-centered systemic reform (TCSR) model was developed by Woodbury and Gess-Newsome (2002) to understand the internal and external factors that influence how instructors respond to pedagogical discontentment. This model includes three factors that could lead to, or inhibit, change. The first factor, systems-as-context, can be thought of as structural and cultural support for instructional change. The second factor, intent-of-reform, is the purpose or goal of the reform. The third factor, teacher thinking, describes teachers' beliefs about the area of focus for reform (Woodbury and Gess-Newsome, 2002; Gess-Newsome et al., 2003).

Gess-Newsome et al. (2003) used the TCSR model to frame their study of three science professors engaging in a teacher reform project focused on integrating active-learning techniques into their classrooms. To challenge the barrier of systems-as-context, structural barriers such as time and money were reduced through an NSF grant. The removal of these barriers was found to be insufficient to move professors toward student-centered methods. As for teacher thinking, Gess-Newsome et al. (2003) found that, of the three professors, only the professor who experienced pedagogical discontentment began to successfully integrate more student-centered teaching methods into daily teaching practice. This professor, unlike the other two more experienced professors, had a mentoring relationship that may have provided support as he worked toward aligning teaching beliefs with practice (Gess-Newsome et al., 2003). Thus, by looking at systems-as-context, intent-of-reform, and teacher thinking, Gess-Newsome et al. (2003) were able to gain a clearer idea of why these three professors moved toward or away from integrating more active learning in their classrooms.

In their study of college professors who were attempting to improve secondary school STEM education while simultaneously shifting to more student-centered pedagogies in their classrooms, Olitsky (2015) found instances of dissonance that both encouraged and discouraged pedagogical change. Identifying a conflict between their emerging beliefs about student-centered practices and their current teaching practices could encourage instructors to integrate more student-centered methods but could also lead to the rejection of these new beliefs. For instance, professors who incorporated more student-centered methods faced negative responses from students or colleagues, leading to dissonance between their beliefs about the positive benefits of student-centered teaching and the negative feedback resulting from its implementation. Olitsky (2015) found that "a key issue influencing the degree of change is whether faculty members experienced a sense of professional community focused on instructional reform within their own departments" (p. 637). Professors with less experience in student-centered teaching who were involved in professional communities of instructional reform persisted in integrating student-centered methods, while instructors who faced a lack of community commitment often saw little to no change in their teaching.

Communities of Practice. To that end, this study also draws on the concept of communities of practice, particularly within the field of STEM education. Communities of practice exist in many facets of society in which people come together to learn through apprenticeship-like experiences within a community focused on developing certain skill sets (Wenger, 2000; Amin and Roberts, 2006). Members of communities of practice come 
together under a collective understanding of the purpose of the community, mutual engagement within the community, and shared resources, such as concepts, language, and tools, to fulfill their communities' purpose (Wenger, 2000). Communities of practice often appear in the forms of craft, professional, expert, or virtual typologies, each with its own forms of social interactions, innovation, and organizational dynamics (Amin and Roberts, 2006). The communities of practice discussed in this paper are professional communities intended to support anatomy and physiology instructors as they expand their pedagogy to include active-learning techniques.

As highlighted by Olitsky (2015), communities of practice can provide STEM professors with the support necessary to make changes to their teaching. Glaze-Crampes (2020) defines communities of practice as "expert communities that share goals, structures, expectations, and practices" (p.1). When oriented toward a focus on student learning outcomes or enacting instructional reform efforts, communities of practice often take the shape of professional learning communities (Olitsky, 2015; Glaze-Crampes, 2020). As STEM educators become more committed to engaging in instructional reform efforts, they are drawn further into professional learning communities, which "provide means for the development of members' practice and identity through authentic participation and construction of meaning" (Glaze-Crampes, 2020, p. 3).

We find that conceptual change theory, with a specific focus on how the concept of pedagogical discontentment acts as a catalyst for change, is useful in understanding our findings from the CAPER project. We also recognize the evaluative power of the TCSR in gaining a better understanding of how structuralcontextual factors play into responses to pedagogical discontentment and lasting change in instructor practice (Woodbury and Gess-Newsome, 2002). Finally, we consider the idea of how communities of practice support instructors in making lasting changes to their teaching practices.

\section{METHODS}

The study uses both qualitative and quantitative methods to address two research questions: 1) How, if at all, did participants in the CAPER program demonstrate a change in beliefs or attitudes regarding their teaching practices? 2) How, if at all, did participants in the CAPER program enact changes in pedagogy to incorporate active learning into their classrooms? The qualitative portion of this study used semistructured interviews to evaluate possible changes in beliefs or attitudes resulting from the CAPER PD program. These interviews also provided insights into whether and how the CC instructors enacted changes to their teaching pedagogy as a result of participating in the CAPER program. The quantitative portion of this study used two sets of surveys that each CC instructor completed at three different points in the study. The data from these surveys were used longitudinally to measure whether CC instructors in the CAPER program incorporated active learning into their classrooms. For both the quantitative and qualitative portions of this study, data were collected from each of the 12 CC instructors at three time points: at the beginning of the project, after the HAPS-I pedagogy and educational research course, and after their research projects were complete. All data-collection procedures were reviewed and approved by the University of Minnesota IRB under the name STUDY00007411.

\section{Qualitative Methods and Analysis}

We examined changes in teacher attitudes and beliefs using interviews based on the Teacher Beliefs Inventory (TBI; Luft and Roehrig, 2007). The TBI was originally developed from the analysis of semistructured interviews to track the development of secondary-school science teachers' beliefs over time. For the CAPER project, we conducted an adapted TBI interview for human anatomy and physiology instructors with the wording changed slightly (Mattheis and Jensen, 2014). We did not find any indications that the use of the TBI with CC instructors rather than secondary-school teachers impacted the findings. Additional questions concerning the backgrounds of instructors and their experiences with the CAPER project were added to each of the three interviews (see Appendix 3 in the Supplemental Material). The first-year participants were also interviewed a fourth time after their involvement with CAPER was complete; this interview focused on factors of the CAPER project that influenced pedagogical change.

The TBI interview protocol includes its own coding procedures used to categorize a teacher's beliefs as traditional, instructive, transitional, responsive, or reform based. In accordance with the TBI coding protocol (A.R.H. and L.S.) two coders separately read through interview transcripts and categorized participants' responses following guidelines and example responses provided by Luft and Roehrig (2007). The (A.R.H. and L.S.) coders subsequently met to discuss their coding and finalize the category for each response. We (A.R.H. and L.S.) completed this process for each participant for each of their three interviews to determine whether the categorization of their beliefs changed over time (i.e., a participant shifted from instructive to responsive).

However, (A.R.H. and L.S.) we realized that the CC instructors shared important insights that did not fit into the TBI coding scheme, so we chose to re-analyze the interviews using open coding. Two researchers (A.R.H. and B.B.) went through three rounds of coding independently, with meetings in between each round to discuss and refine themes. In qualitative research, "Codes are prompts or triggers for deeper reflection on the data's meanings. Coding is thus a data condensation task that enables you to retrieve the most meaningful material, to assemble chunks of data that go together, and to further condense the bulk into readily analyzable units" (Miles et al., 2014, p. 80). The first round of coding was open, descriptive coding to identify themes that appeared in several interviews across instructors and interview rounds (Miles et al., 2014). After identifying themes independently, the researchers (A.R.H. and B.B.) met to review the themes they had identified and to create subthemes (Miles et al., 2014). This discussion was followed by two rounds of selective coding to iteratively analyze the data against themes identified during the first round of coding and adjust the themes accordingly (Corbin and Strauss, 1990; Miles et al., 2014). These themes included: systems-as-context, pedagogical discontentment and shifting toward active learning, pedagogical changes from pedagogical discontentment, and changing perceptions of educational research. A codebook including each theme, a description of the theme, and representative quotes is included as Appendix 4 in the Supplemental Material.

We (A.R.H. and B.B.) found that our themes aligned closely with aspects of pedagogical discontentment, the TCSR model, and communities of practice and therefore chose to construct 
our theoretical framework around these topics. As such, we have divided our qualitative findings into sections that reflect aspects of the TCSR model and communities of practice. Our first section is entitled "systems-as-context," which is the first of the three factors in the TCSR model. Our second, third, and fourth sections focus on how instructors' beliefs changed during their participation in this program, which we see as aligning with the teacher thinking factor of TCSR. We discussed the intent-of-reform factor in our introduction to the CAPER project.

Trustworthiness. According to Guba (1981) and Schwandt et al., (2007), establishing the trustworthiness of qualitative analysis work should address four criteria: credibility, transferability, dependability, and confirmability. Credibility can be established by strategies such as using multiple forms of data collection, gathering data over a long time period, discussing findings with peers and participants, and including negative cases in the study (Guba, 1981; Schwandt et al., 2007). For our study, we fulfilled the credibility criterion by gathering data over 2 years using multiple qualitative and quantitative research instruments that allowed us to cross-check our findings. In addition, by having two researchers from different domains (education and STEM) analyze the qualitative data through a series of individual and group sessions, we approached the data from two perspectives and found a middle ground of understanding. As for transferability, Guba (1981) and Schwandt et al. (2007) call for thick description, or a very detailed description of the environment within which the data are being collected, in order for readers to recognize similarities or differences between this research site and other sites. As this was a study conducted mainly online, thick description was not possible. We have, however, provided a detailed description of the CAPER project and the data-collection methods that we used to allow readers to determine transferability. In terms of dependability, we saw similarities between our two cohorts as well as within each cohort. Finally, the CAPER project was externally evaluated at the end of each year, ensuring that we were engaging in effective PD and were collecting reliable data (Guba, 1981; Schwandt et al., 2007).

\section{Quantitative Tools and Analysis}

We addressed our second research question regarding potential changes in teacher practices using two quantitative surveys: the TPI developed by Wieman and Gilbert (2014) and the Postsecondary Instructional Practices Survey (PIPS) developed by Walter et al. (2016). In brief, the TPI is a 72-item questionnaire designed for math and science faculty that evaluates an instructor's use of a wide range of teaching practices in one course. TPI items are organized into eight thematic categories: course information provided, supporting materials provided, in-class activities, assignments, feedback and testing, other forms of assessing learning, training and guidance of teaching assistants (TAs), and collaboration and sharing in teaching. For example, instructors (or external observers of instructors) are asked to indicate whether students are provided with course information such as a list of competencies that will be developed (course information provided category); whether supporting materials such as worked examples or solutions are available (supporting materials provided category); and whether feedback sources such as grading rubrics and answer keys are provided (feedback and testing category). Questionnaire items also assess the average number of times various activities such as small-group discussions occur per class. The TPI scoring rubric assigns points to each use of an evidence-based teaching practice and no points for use of practices lacking supporting evidence. Scores are summed across items to create an "extent of use of researchbased teaching practices" or ETP score per thematic category, such that a higher ETP score reflects more use of evidence-based practices. A total ETP score, with a maximum value of 67 , can also be calculated to reflect the overall use of evidence-based practices in a given course. The complete scoring guide and scoring template for the TPI are available at https://cwsei .ubc.ca/resources/tools/tpi (Wieman and Gilbert, 2014). See Appendix 1 for the full TPI data).

The PIPS is a 24-item Likert-scale survey designed to assess instructional practices of postsecondary instructors, regardless of discipline. The Likert scale includes the following options and score values: Not at all descriptive of my teaching (0), Minimally descriptive of my teaching (1), Somewhat descriptive of my teaching (2), Mostly descriptive of my teaching (3), and Very descriptive of my teaching (4) (Walter et al., 2016). The PIPS survey is scored using either a two-factor model (instructor-centered or student-centered practices) or a five-factor model (student-student interactions, content delivery, formative assessment, student-content engagement, and summative assessment; Walter et al., 2016). We scored the PIPS survey using both types of models, but as the two-factor model illustrates instructor- and student-centered practices more clearly, we have chosen to include and discuss only the two-factor model in this article. As we used only the two-factor model for this paper, we will further elaborate on this particular scoring model. Within the two-factor model, instructor-centered practices are measured through nine questions such as "I guide my students through major topics as they listen and take notes" (Walter et al., 2016). Student-centered practices are measured through 13questions, including "I structure class so that students regularly talk with one another about course concepts" (Walter et al., 2016). To calculate the PIPS scores for either model, the researchers found the actual sum of the scores associated with responses to survey items within the specific category, divided this by the maximum possible sum for those survey items, and multiplied that result by 100 (Walter et al., 2016). While we describe only the results of the two-factor model in our findings, all descriptive data for the PIPS are included in Appendix 2 in the Supplemental Material.

Both surveys were analyzed according to scoring instructions and tools provided in articles by Walter et al. (2016) and Wieman and Gilbert (2014). We did not perform inferential statistical analyses on the survey data outside of using the scoring protocols, because our sample consisted of only 12 participants, six of whom were required to modify their teaching as a result of COVID-19 during the data-collection phase of CAPER. Instead, these quantitative data are presented in a descriptive way to support or dispute our qualitative findings.

\section{FINDINGS}

\section{Qualitative Findings}

In this section we present our qualitative findings organized by theme. As mentioned in the Methods section, these themes include systems-as-context, pedagogical discontentment and 
shifting toward active learning, pedagogical changes from pedagogical discontentment, and changing perceptions of educational research. This section elaborates upon each of these themes, bringing in evidence from our interviews and connecting the experiences of these CC instructors with literature on PD in higher education and conceptual change theory. We have included interview numbers with all extracts in this section to show instructors' change over time.

Systems-as-Context. Woodbury and Gess-Newsome (2002) use the term "systems-as-context" to refer to institutional and structural factors that either support or detract from reformbased change. We use systems-as-context to study the CAPER environment and the institutional environments of participating CC instructors (Woodbury and Gess-Newsome, 2002). Changes catalyzed by pedagogical discontentment often arise in supportive environments and persist in individuals engaged in growth-oriented professional relationships (Woodbury and Gess-Newsome, 2002; Gess-Newsome et al., 2003; Olitsky, 2015). In this section, we look specifically at communities of practice as a supportive factor for pedagogical change and two types of barriers-the barriers to participation in CAPER and barriers to pedagogical change-concerning both their institutional cultures and teaching expectations for CC instructors.

CC instructors' responses to the CAPER environment indicate that it provided a supportive space conducive to experimenting with and conducting classroom research on active-learning techniques (Edwards et al., 2015; Olitsky, 2015; Schinske et al., 2017). They discussed how CAPER provided a space for CC instructors from different institutions to discuss their challenges with teaching and learning in a CC environment and share possible solutions. According to Professor Garcia (interview 3):

So collaboration across, you know, different colleges and across states is really beneficial and powerful because it puts you in contact with individuals that may have a different way of addressing a problem you were seeing in your own classroom, where you wouldn't have ever seen that before. Or they've been able to adopt a resource that's out there that you never knew about.

CC instructors described developing a sense of solidarity around mutual struggles with teaching, learning, and researching in their institutions. They also discussed the benefits of having mentors through the CAPER project who provided support throughout the educational research process. For instance, one instructor, Professor N. Klein, indicated in her third interview that she was already planning on participating in another PD program to benefit from additional mentorship after CAPER ended.

The CAPER project acted as a gateway into anatomy and physiology organizations such as the Human Anatomy and Physiology Society (HAPS), within which CC instructors found a group of like-minded people with whom to share ideas and get feedback. All instructors from the first year presented their educational research projects at the poster session of the annual HAPS conference. Due to delays caused by COVID-19, the second-year cohort hopes to present at the HAPS conference in 2021. Several CC instructors expressed their intentions to con- tinue attending HAPS, and in some cases, to organize similar conferences. These comments indicate the importance of these organizations as long-term communities of practice that will continue to support the PD of CC instructors after CAPER. According to Professor Tabard (interview 3):

I have only been to HAPS once, which was before this [CAPER] all started. And so I was really looking forward to going back and I'm still looking forward to going back but yeah, it's, I think that it [CAPER] has made me become more involved with HAPS for sure. Because now I'm in charge of a regional conference next spring.

The CC instructors' interest in continued involvement with HAPS and other organizations for anatomy and physiology instructors also indicates increased self-efficacy. This self-efficacy is clearly expressed in both Professor Tabard's shift from attending one HAPS conference to organizing a regional HAPS conference after CAPER and Professor Tracy's continued involvement with the anatomy and physiology community discussed in her fourth interview:

McGraw Hill ... invited me to come down for a weekend to do this A\&P teacher symposium to talk about their product, and then to get ideas of what kind of things we would want them to do in that stuff. And I think before CAPER, I would have never went to something like that, you know, but I totally went to it. It was a blast. It was good. I learned a lot about their stuff. And I learned I got another 10 or 15 instructors across the US that now that I can contact and know that they'll talk about stuff with me too. And so I think it just really, it got me back into the game.

Thus, as a result of her involvement with CAPER, Professor Tracy developed the self-efficacy to recognize herself as an anatomy and physiology instructor who can provide others with valuable feedback. Through her experience at the McGraw Hill symposium, Professor Tracy was able to build an even broader community of learning. As discussed previously, both self-efficacy and supportive environments are necessary for instructors to change teaching practices when experiencing pedagogical discontentment (Gess-Newsome et al., 2003; Southerland et al., 2011; Olitsky, 2015).

While the community of practice provided by CAPER, HAPS, and other organizations was conducive to instructor change, the CC instructors' institutions placed many limitations on their use of active-learning techniques and educational research. In terms of structural limitations, CC instructors often discussed their heavy teaching loads and large class sizes as impediments to changing their teaching methods, similar to limitations identified previously by Edwards et al. (2015) and Schinske et al. (2017). Many CC instructors also shared that it was difficult to integrate active-learning techniques into lessons that were taught from strictly organized and time-bound curricula. For instance, Professor Vogelsang (interview 4) shared:

The primary challenge is exactly what I thought it was going to be in the beginning, which is figuring out the time to do all of this. I mean, you teach to, there are a million things that you could do that are creative, but then there's also X amount of content that you have to get through. 
With a large amount of material to cover and limited time in which to teach it, many CC instructors found fully covering all of the learning material difficult enough without the added time spent integrating activities. Many CC instructors also found that their heavy teaching loads constrained the amount of time that they could spend on CAPER work.

If I just had some time, like, I have all these things that I think would work, I just need some time to create them and test them and pilot them and none of us do. We're like running around, barely, you know, barely getting our grades in. Um, and I got this sense actually from other CAPER participants.Professor N. Klein (interview 4)

To address this limitation, Professor N. Klein suggested course releases for future participants to support their ability to focus on and carry out CAPER work.

While some institutions supported CC instructors' participation in the PD and educational research portions of CAPER, other institutions appeared to impede the educational research, as described by Schinske et al. (2017). CC instructors across both cohorts struggled to get IRB clearance for their research with students from their institutions, but all instructors did eventually succeed in receiving IRB approval. According to Professor N. Klein (interview 4), "I couldn't get an IRB, I couldn't get a pass because they kept ignoring me." Several instructors in one particular institution experienced direct interference from their administration. According to Professor Blewett (interview 3): "But with the CAPER project, it has been a nightmare for us. I speak on behalf of my colleagues, it's been an absolute nightmare. They have blocked us, they have interfered."

As described in this section, the system-as-context placed certain limitations on what the CC instructors were able to do in terms of integrating active learning or engaging in educational research. However, despite these limitations, many instructors discussed their growing pedagogical discontentment, increased self-efficacy, and change in beliefs about active learning and educational research that, in a few cases, even led to change in pedagogy.

Pedagogical Discontentment and Shifting Perspectives toward Active Learning. Explored as a construct by Southerland et al. (2011), pedagogical discontentment "reflects a state of cognitive conflict that exists when an individual recognizes a mismatch between [their] science teaching pedagogical goals and classroom practices" (p. 299). Many instructors expressed such conflict, and many also related their pedagogical discontentment with a desire to improve teaching practices. In this section, we explore the progression of discontentment and shifting perspectives across time through the cases of two CC instructors-Professor Dugan and Professor Tracy.

Professor Dugan joined the CAPER project with the desire to increase his use of active-learning techniques. As he stated in interview 1, "That's exactly why I was involved in this because I understand the significance of active learning, and it's just been very hard for me." This indicates that Professor Dugan was experiencing pedagogical discontentment before the CAPER project and it was a motivating factor in his choice to participate. While expressing a recognition for the importance of active learning, he simultaneously resisted embracing it in his classroom.
It's kind of embarrassing because I've been to the seminars and this and that and I know the benefits of it [active learning], it's just-I look at it like people who have a hard time admitting to something, where they have to accept it first, and I am having a hard time doing that, to be honest.-Professor Dugan (interview 1)

This difficulty engaging with active learning continued until the end of the CAPER course on active learning and classroom research. Professor Dugan stated in interview 2, "I mean, I'm trying so far, and it's just-I'll admit, I mean, it's old dog, new tricks, you know." However, he also acknowledged that he learned how to integrate active-learning techniques into his lessons through this course, which may have supported his sense of self-efficacy.

I guess the idea of non-graded activities actually kind of surprised me because I think back to my own experience, I don't remember instructors ever using nongraded activities ... Or just the number of things that are out there that can be done in the classroom ... I never really had an education practice type course. I mean I don't know how many people actually did, of my generation or older, and you're just expected to be an instructor when you're not really trained as an instructor. So, specific examples really helped.-Professor Dugan (interview 2)

Professor Dugan's surprise at the existence of pedagogical techniques (such as nongraded activities) that were not employed by his instructors supports previous educational research findings showing that educators often teach how they were taught (Hardre, 2012; Oleson and Hora, 2014; Seithers et al., 2020).

After completing his classroom research, Professor Dugan discussed how he had become more aware and reflective about his teaching, shifting his focus from content to process. According to Professor Dugan (interview 3):

You're more introspective. You see what you're doing yourself. I think that's one of the things that maybe changed me is looking more at exactly how I'm doing this. Where for a long time, I was kind of focusing on content and not process. And now I think I'm looking a little bit more about the process and there $\ldots$ all the other possible alternatives that are out there.

A year after completing the CAPER project, Professor Dugan reflected on his teaching and the CAPER project in a final interview. According to Professor Dugan (interview 4):

I have changed somewhat. I will admit I am slow to change. Because with personal reflection, I realized what I like about teaching and that is the interaction. And for a while, I was very interested in POGIL [process-oriented guided-inquiry learning]. But the concept of the facilitator position again was very difficult for me to accept personally simply because I like the interaction and to be having to stand off and just, you know, try not to be involved. You know, I mean, as POGIL goes, you want to be the facilitator, but you don't want to be part of the conversation and personally, that's very hard for me. I'm not saying that's wrong, I'm saying that I might be the one that's wrong in this case. And that's where I started was very much wanting to be involved in the conversation. However, I'm 
beginning to notice, starting back with this course, I'm recognizing there are other alternatives where you're not actually having to sacrifice that part of things and still change. So I would say, you know, much of me hasn't changed, but I am moving more toward active learning, getting people involved, that kind of thing. So, yeah, I'm kicking and screaming moving into the future.

In this interview, Professor Dugan indicated a slight change in perspective as a result of the CAPER program. He discussed aspects of his professional identity that conflicted with incorporating POGIL, a teaching approach that emphasizes student-centered, group-oriented learning, into his pedagogy, including the importance of personal interaction with his students. However, he acknowledged that he was exposed to and began experimenting with active-learning techniques that do not require complete distance between students and the instructor. Professor Dugan's case is interesting, in that he describes learning about and implementing active learning in his classroom during and after the CAPER program, while simultaneously maintaining a resistance toward the concept of active learning based on conflicts with his identity as an educator. This phenomenon may be related to the iterative nature of experience and belief change, in which experiences with active learning in the classroom contribute to changes in beliefs, which in turn encourage pedagogical change (Oleson and Hora, 2014; Andrews and Lemons, 2015; Bonner et al., 2020).

Similar to Professor Dugan, Professor Tracy began the CAPER program with a discomfort toward allowing students to learn independently through active learning but also with the acknowledgment of the importance of doing so.

I guess I think part of my little issue is it's hard for me to give up that, to put that ownership on the students, to trust that they're gonna learn the stuff without me having to help them. That sounds so horrible--but you know that's-I'm so used to kind of bringing them through, and I know if they can learn it on their own, if they have to figure it out on their own, they're gonna understand it, they're gonna remember it better, it's just - that's not the way I ever learned how to do it, and I need to learn how to teach that way. I need to learn how to help them figure these things out on their own.-Professor Tracy (interview 1)

Her acknowledgment of the benefits of active learning and her own need to learn more about it indicate pedagogical discontentment with her teaching. She discusses in interview 2 how she learned many active-learning activities in the CAPER course work that were simple to integrate into her lessons, but she still needed more motivation to take action.

It's the whole getting off your butt and doing them. You know?-That once you implement them in the classroom, they're not that difficult. So, kind of just a lot of motivation to get out there and do a little bit better than I've been doing, I mean, you know, I don't think I'm doing a total crappy job or anything-but we can always improve. And I think it really opened my eyes to the ways that just tiny little things, you know, maybe like that muddiest points [exercise] or something - can make a big difference in the classroom in allowing my students to really let me know what's going on with them.-Professor Tracy (interview 2)
Her mention of not teaching poorly but having room for improvement and needing a lot of motivation to make small improvements suggests that her pedagogical discontentment and self-efficacy have not yet reached a balance necessary for making changes to her teaching.

However, as Andrews and Lemons (2015) discussed, Professor Tracy appeared to become more interested in making changes after seeing student responses to active learning in the classroom. After carrying out her classroom research project, Professor Tracy described in interview 3:

When they're doing those worksheets and different things, when I see them, kind of ... you almost see that light bulb above their head, you almost see that moment when their face lights up, and they're like, oh, okay, yeah,... and then really, you know, then this is the next step. That's when I feel like they have the learning when they're actively doing things. So I need to add more of that to my lecture, I need to quit the lecturing and add more of the active stuff.

As she describes, seeing students' faces light up from moments of active learning catalyzed Professor Tracy to begin changing her perspective from changing little things in her teaching to moving away from lecturing and toward active learning. A year later, when Professor Tracy was interviewed for the fourth time, she indicated that participating in the CAPER program had changed her perspective toward active learning. While qualifying that the COVID-19 pandemic has affected the amount of change she has been able to make, she remained focused on changing her courses slowly to integrate more independent critical-thinking activities, intending to make broader changes during a future sabbatical.

So it's really opened my eyes to different ways of doing active learning. And that I can just do a little bit at a time. Any little bit is going to help my students to learn a little better. Anytime I can get them to engage and do some thinking on their own, some critical thinking, they're going to do better. So it's, it's changed the way I teach. And it's molded the way I would want to teach in the future when this craziness is over. And I have a little more time to prep for different things. That's, that's the road I'm going. I have a sabbatical, not next year, but the year after, and I'm hoping to flip a classroom and do all sorts of active-learning stuff and you know, so it's just completely changed the way I teach and help me know that I can do that I can change the way I teach. So that's great.-Professor Tracy (interview 4)

Similar to many CC instructors who participated in the CAPER project, Professor Tracy seems to have changed her perspective toward active learning. In the beginning, she struggled to let her students learn without her guidance, but by the end of the project, she discussed small changes that she was making to her courses and plans to make larger changes. This change in beliefs was common among the 12 CC instructors.

The case studies of Professor Dugan and Professor Tracy are illustrative of how pedagogical discontentment can catalyze pedagogical change, a process shared in varying degrees by all 12 CC instructors. Both Professor Dugan and Professor Tracy expressed some degree of change in beliefs from the beginning to the end of the CAPER project, although Professor Dugan 
remained more resistant to reducing his interactions with students. They both began with an initial level of pedagogical discontentment and an acknowledgment of the importance of active learning but lacked concrete methods to incorporate active learning in their classrooms. After gaining knowledge of different active-learning techniques through the CAPER course, they began to make small changes to add opportunities for active learning in their lessons. Through carrying out their classroom research projects, Professor Dugan and Professor Tracy became more reflective of their teaching and student reactions to it, which encouraged them to continue making small pedagogical shifts. Both of them also mentioned making small changes to their lessons to integrate active-learning opportunities that fit their current comfort levels. While neither CC instructor had made large, concrete changes to their courses by the end of CAPER, they both expressed more positive attitudes toward active learning and intentions for future pedagogical changes that worked with their identities as educators.

Pedagogical Changes from Pedagogical Discontentment. After a year in the CAPER program, some instructors indicated changes not only within their pedagogical perspectives but within their teaching practices. Professor N. Klein described developing the video lectures for a flipped-classroom model while shifting to online learning during the COVID-19 pandemic.

I can record all the lectures and post them. But then in class when I actually am with them, then we just do active engagement, for the most part, maybe a little bit of lecturing because sometimes they're tired. And they want to take notes for a few minutes. But that's the kind of classroom I wanted to try anyway, eventually was to flip it more. And I just didn't have time to record lectures. Now I'm like, "Well, now I have no choice." And, do it, you want to try that. So I'd have short 10-minute lectures, and I'd say watch these three 10-minute lectures or whatever before you come to class. And then we'll do activities.-Professor N. Klein (interview 4)

While Professor N. Klein's engagement with active learning was by far the most drastic, Professor Jones and Professor Plum also discussed making changes in their classrooms based on active-learning techniques taught in the CAPER course work. According to Professor Jones (interview 3):

Well, as I've learned in this course, students learn best by teaching it. So I would say that I start out with them hearing it, right. I try to explain it to them and make it relatable. I will then often have them draw, come draw actual anatomy, and then overlay that with concepts. So like, I'll have them draw the heart. But then I'll also have them use different colored crayons, colored pencils, markers to trace the flow of blood through the heart, whether it's oxygenated or you know, low oxygen, and, and then that's something that I would have them doing for the review at the board. So can they go to the board and teach it? Can they draw or trace this flow of blood through the heart? Do they really understand what's happening? And then, you know, have them explain it to us?

Professor Jones designed lessons that progress from providing the knowledge to asking students to explain anatomical concepts by themselves to support their understanding of the content. Professor Plum integrated a variety of active-learning activities into her classroom, including think-pair-share, case studies, and cooperative quizzes.

I've introduced some new things since CAPER. I've been doing a lot more the think-pair-share and, you know, giving students a question and then having them talk it over with their neighbor and then I'd even have, you know, those pairs check with another pair to see, you know, if they got the same answer or whatever, and then we discuss it. So I've been doing a lot more active learning. So the think-pair-share, I do the case studies. And then with my research, I did the, oh my gosh, I'm just, like, blanking on the cooperative quizzes.-Professor Plum (interview 3)

These three professors had different approaches to integrating active learning into their classrooms, from Professor $\mathrm{N}$. Klein's complete shift in classroom structure to Professor Plum's integration of activities into her regular class schedule.

Changing Perceptions of Educational Research. Another outcome of the CAPER project was that instructors became more connected with educational research as a source of knowledge and space to share their classroom findings. Many instructors attributed changes in their practices to an increased awareness of and participation in this field.

Like many CC instructors, Professor Vogelsang frequently tries new teaching and learning strategies in her courses. Before CAPER, this process was following a "trial and error" approach, but her exposure to formalized education research changed how she approached her classroom. According to Professor Vogelsang (interview 3):

Well, I've always experimented with my classes, but just sort of informally, never really recording data. And so I think that primarily, what really has changed is just me seeing that the process could and maybe even should be formalized so that I actually get the output that allows me to know whether what I'm doing is working or helpful to my students.

Professor Vogelsang's involvement with CAPER has enlightened her concerning the application of data collection and analysis in her courses, as well as their use improving her instruction. Many of the CC instructors expressed similar sentiments; through increased exposure to published education research, they have gained an understanding of its usefulness in their personal practices. Instructors made clear the role of their research in influencing their self-efficacy surrounding the implementation of active-learning techniques, as it serves as an impartial measurement of the effectiveness of their instruction and gives credibility to their efforts.

Another outcome of this aspect of the project was that instructors began to consult literature more frequently. This led to instructors carefully considering how and when to incorporate active learning techniques and more broadly exploring the potential consequences of changes they plan to make in their classrooms. Professor Vogelsang (interview 4) recounts how her exposure to educational research through CAPER saw her teaching choices become more informed by scholarly literature, 
and how this helped her overcome perceived barriers and adapt to an online environment.

I wasn't aware of how much peer-reviewed information there was out there about the efficacy of different teaching practices. I also was unaware about how different teaching practices impact different groups of students. And because I'm now aware that that exists, I try to check out the peer-reviewed literature, when I'm thinking about making changes in my class. So even things like going online, the first thing that I did that didn't seem to have occurred to some of my colleagues was to go and look at the literature about effective online teaching practices and to assess whether synchronous or asynchronous would work better. And you know, how it impacts students in different ways.

Vogelsang expresses a shift in her attitude about activity implementation in her courses, now basing her planning heavily on published research and demonstrating a far more careful consideration of how changes she makes impact her students. Similarly, Professor N. Klein (interview 4) explained how her data collection in her courses guides her classroom practices going into subsequent semesters.

I think that at the beginning, there were certain assumptions that I had, that there were certain evidence-based teaching practices that always worked. And I don't know, I believe, I think that they work in certain contexts for sure. And that really, you know, I found in my study results I wasn't expecting, and I think we all did, you know, in different ways.

Professor N. Klein makes very clear how data gathered in her courses broke down her assumptions about the effectiveness of certain active learning techniques. Many instructors shared the opinions of Vogelsang and N. Klein, expressing that both published research and their data influence their teaching practices more heavily following their involvement with CAPER. This universal shift was attributed to their exposure to formalized educational research through the project, with many participants describing a lack of awareness about the available literature beforehand.

\section{Quantitative Findings}

While the qualitative data indicated potential changes in attitude, there were few indications of change in pedagogy from the TPI or PIPS surveys. The TPI scores of self-reported instructor practices, including course information provided, supporting materials provided, in-class activities, assignments, feedback and testing, other forms of assessing learning, training and guidance of TAs, and collaboration and sharing in teaching show little change across the three rounds of surveys for either year (Wieman and Gilbert, 2014).

Table 2 presents mean ETP scores, which measure the extent of evidence-based teaching, from the TPI derived from each of the three rounds of surveys taken by year 1 and 2 cohorts. Both cohorts scored in the midrange of the ETP across the year that they participated in CAPER. Very little increase or decrease is observed for each of the eight categories individually across the three rounds of surveys or between cohorts. A small increase was observed in the "in-class features and activities" category in both years 1 and 2, which will be discussed and
TABLE 2. TPI data

\begin{tabular}{lc}
\hline Year and round & Mean total ETP score (SD) \\
\hline Y1R1 & $33.1(4.1)$ \\
Y1R2 & $37.9(4.0)$ \\
Y1R3 & $35.8(3.8)$ \\
Y2R1 & $33.8(3.9)$ \\
Y2R2 & $36.2(4.3)$ \\
Y2R3 & $36.6(1.9)$ \\
Maximum possible & 67
\end{tabular}

contextualized within the CAPER environment in the Discussion section.

Similar findings are indicated by the PIPS data, which measure the proportion of classroom time spent on activities considered student centered or instructor centered. In both cohorts, instructors reported engaging in student-centered instruction within a range of $40 \%$ to $50 \%$ of the time and instructor-centered teaching between $50 \%$ and $60 \%$ of the time (see Appendix 2 in the Supplemental Material for descriptive data).

In summary, ETP scores from the TPI survey indicate that the instructors from both cohorts use half instructor-centered teaching practices and half evidence-based teaching practices. PIPS data indicate that instructors from both cohorts engage with student-centered teaching practices and instructor-centered teaching processes around half of the time. Both sets of descriptive data show little increase or decrease in CC instructors' engagement with evidence-based teaching practices across their yearlong participation in the CAPER project.

\section{Instructor Interactions with Quantitative Data}

As mentioned in the Methods section, first-round CC instructors were asked to view and respond to graphical representations of their individual PIPS results for questions on student-student interactions, content delivery practices, formative assessments, and student-content engagement from three time points: pre-CAPER, after the HAPS-I course, and after completing their educational research projects during their fourth-round interviews. They responded to this lack of change in their self-reported quantitative data in a variety of ways, including questioning their responses to the surveys, discussing increased awareness of gaps between their teaching and how they would like to teach, explaining how time limitations impact their ability to change, and parsing out relationships between different data points. For instance, Professor Vogelsang discussed how three of the four charts reflected the changes she expected, while she may have misunderstood the lecture-based learning questions. Professor Vogelsang (interview 4):

Does this mean I engage in lecture-based practices more? Maybe I just didn't understand the question. I do less of me talking than I used to. And especially in one class, the physiology class, the one that I implemented CAPER in. So I don't think that adequately reflects what I think and reflects me misunderstanding the question.

Professor Vogelsang showed a potential imbalance of self-efficacy and pedagogical dissatisfaction, focusing mainly on how her responses to the survey questions did not reflect her 
current teaching practices. Somewhat surprised by the lack of change, several professors discussed their data in relation to time, suggesting that they had more time to make changes in their classrooms after finishing CAPER. According to Professor Tracy (interview 4):

I do think that it [the PIPS data] has made me more aware that I would like to be doing more active learning. And I realized that I'm very lecture heavy, and I need to add more activities and things for the students to do ... As I was learning, and growing, and realizing that, you know, there is a different way to teach, I was understanding that I wasn't really doing it that way. I thought that I would have gotten, you know, better at the active-learning stuff as the semester went on. But then there's also the, I mean, it takes a while to add new things to your classes. And I think that probably during that CAPER project when we were so busy with the project and any extra time I kind of had that I could have possibly put toward changing my teaching was almost eaten up by that ... I mean, that's, you know, part of what's going on but now I'm used to spending more time, my extra time for the teaching I can spend getting my classes to be better.

Professor Tracy expressed how her PIPS data helped her to realize that she was not including as much active learning as she had expected into her lessons and that she now had time to make changes in her teaching and reduce those feelings of pedagogical discontent. Professor N. Klein also processed her PIPS data in a reflective and introspective way. When processing the reported decrease in student-content engagement and increase in student-student interaction, Professor N. Klein (interview 4) stated:

And then student-content engagement, it went down. I wonder if that was my own, because I don't feel like it changed. Um, because when I have time we always do clinical examples now and I'm like, did I do any less? Any fewer? Actually, I might have. And the reason might have been because I had less time. You know, because they were doing student-to-student interactions, you know, you have like, five less minutes. Sure, it is a trade-off ... I think actually, that is accurate, because I did more student-student engagement. So I mean, that's something to know because like, you don't want to take that content out, but maybe find a different way to deliver.

Professor N. Klein saw student-content engagement and student-student engagement as related and recognized a need to reach a balance between the two. Although the quantitative data are not particularly revealing, the ways each of these instructors reflected on their PIPS data help the researchers to understand more about the CC instructors' progress through pedagogical dissatisfaction toward change in their instructional practices.

\section{DISCUSSION}

As described in the Findings, the quantitative data reveal very little change in self-reported pedagogical practices across CC instructors' yearlong participation in CAPER. Both the TPI and PIPS data indicate that instructors engaged with active learning about half of the time throughout their participation in CAPER. However, first-round CC instructor responses to their own PIPS data were revealing about their internal processes related to pedagogical discontent and instructional change. While they often expressed surprise or disappointment in the lack of measurable change in their classrooms over the year, the CC instructors also recognized that they were still moving toward integrating active learning and the PIPS data reminded them of that fact.

In terms of systems-as-context, participating CC instructors found supportive communities of practice both in CAPER and in the broader anatomy and physiology education community. While previous research has suggested the importance of localized communities of practice for pedagogical change, few have discussed the supportive nature of broader professional communities (Woodbury and Gess-Newsome, 2002; Gess-Newsome et al., 2003; Olitsky, 2015). Our findings suggest that CC instructors who participated in CAPER have continued to rely on professional communities for PD opportunities and continuous support. However, in a CC system focused on teaching, the CC instructors faced a variety of barriers to integrating active learning into lessons or conducting educational research. These barriers reflected those found in previous studies, including time limitations, heavy teaching loads, and a lack of institutional support (Oleson and Hora, 2014; Edwards et al., 2015; Schinske et al., 2017). The HAPS-I course work and educational research required by CAPER compounded these challenges, making it difficult for instructors to learn about, study, and enact changes in their classrooms simultaneously.

Many instructors joined CAPER to learn about, research, and integrate active learning into their pedagogy and described varying levels of pedagogical discontentment through recognizing the importance of active learning and noticing a lack of student interaction in their pedagogy. Scholars have previously found that a proper balance of self-efficacy and pedagogical discontentment can lead to pedagogical changes, but have not necessarily addressed how these two factors interact with ambivalence toward the proposed reforms (Gess-Newsome et al., 2003; Southerland et al., 2011; Olitsky, 2015). While some instructors were ambivalent toward active learning when they joined CAPER, they were able to identify the specific aspects that they found difficult-such as allowing students to learn independently-and found specific active-learning techniques that matched their beliefs about teaching. By the end of the CAPER project, most instructors expressed positive attitudes toward active learning and intentions for future pedagogical changes in their classrooms. Few instructors, however, described concrete large-scale changes in their teaching by the end of CAPER.

\section{IMPLICATIONS}

This research has left us with three main implications, one regarding study methodology and two regarding PD. First, our original intent while conceptualizing this paper was to present a balance of qualitative and quantitative findings. However, we quickly found a gap between the lack of change indicated in the quantitative data and the clear changes present in the CC instructors' interviews. While the quantitative data indicated little change in pedagogical practices among CC instructors during their participation in CAPER, the qualitative data indicated that these instructors shifted their attitudes toward active-learning techniques but had not yet reached a point of pedagogical change. Without carefully considering both the 
quantitative and qualitative data, these points may have been overlooked and the CAPER project may have been deemed unsuccessful in encouraging CC anatomy and physiology instructors to engage in active learning. Thus, adding qualitative methods and other quantitative instruments to pedagogical change studies can provide important insights into changes in attitudes or beliefs concerning active learning. Taking our qualitative findings into account, we have found that many instructors experienced pedagogical discontentment, learned active-learning techniques to address this dissatisfaction in the HAPS-I course, saw how their students interacted with these techniques through their educational research, and changed their beliefs toward active learning as a result.

In terms of implications for future PD programming, the CAPER team found that both the pedagogical and research aspects supported CC instructors in their engagement with active learning. Many participants described how the clear examples of active-learning techniques included in the HAPS-I course filled gaps in their previous knowledge. The research aspect gave CC instructors the opportunity to study the impacts of select active-learning techniques on their students, giving them more confidence in the effectiveness of these methods. Several instructors also mentioned the ways in which becoming involved in educational research on anatomy and physiology courses drew them into communities of practice that could sustain their involvement and interest in both research and active learning. These findings indicate that combining pedagogical training with educational research opportunities in PD programming can appeal to both the researcher and educator identities of CC instructors. Through participation in HAPS and Society for the Advancement of Biology Education Research conferences, the CC instructors increase their involvement in the broader community of anatomy and physiology educational researchers, where they can share the ways in which a diverse group of CC students experience active learning in their classrooms.

While our findings indicate that CAPER did facilitate pedagogical discontentment and changes in beliefs about active learning, structural barriers and the length of the program prevented most instructors from enacting large-scale pedagogical changes. Therefore, we support several scholars in suggesting that future iterations of CAPER and similar PD programming should consider distributing required activities across a longer period of time and offering course reductions for participating CC instructors to give them more time to learn about and enact pedagogical change (Edwards et al., 2015; Schinske et al., 2017). As part of extended PD programming, we would suggest a longer span of data collection to measure pedagogical change over several years. A longitudinal study could allow researchers to better understand the long-term impacts of PD programming on CC instructors' integration of active learning in their classrooms.

\section{ACKNOWLEDGMENTS}

The CAPER project was funded by the NSF under award no. 1829157.

\section{REFERENCES}

Amin, A., \& Roberts, J. (2006). Communities of practice? Varieties of situated learning paper prepared for: EU Network of Excellence Dynamics of Institutions and Markets in Europe (DIME). Retrieved April 30, 2021, from https://www.dime-eu.org/files/active/O/Amin_Roberts.pdf
Andrews, T. C., \& Lemons, P. P. (2015). It's personal: Biology instructors prioritize personal evidence over empirical evidence in teaching decisions. CBE-Life Sciences Education, 14(1), ar7. https://doi.org/10.1187/ cbe.14-05-0084

Bonner, S. M., Diehl, K., \& Trachtman, R. (2020). Teacher belief and agency development in bringing change to scale. Journal of Educational Change, 21(2), 363-384. https://doi.org/10.1007/s10833-019-09360-4

Corbin, J. M., \& Strauss, A. (1990). Grounded theory research: Procedures, canons, and evaluative criteria. Qualitative Sociology, 13(1), 3-21. https:// doi.org/10.1007/BF00988593

Edwards, A. R., Sandoval, C., \& McNamara, H. (2015). Designing for improvement in professional development for community college developmental mathematics faculty. Journal of Teacher Education, 66(5), 466481. https://doi.org/10.1177/0022487115602313

Feldman, A. (2000). Decision making in the practical domain: A model of practical conceptual change. Science Education, 84(5), 606-623. https:// doi.org/10.1002/1098-237X(200009)84:5<606::AID-SCE4>3.0.CO;2-R

Flynn, J., James, R., Mathien, T., Mitchell, P., \& Whalen, S. (2017). The overlooked context: Pedagogies for engagement and empowerment at the community college. Curriculum \& Teaching Dialogue, 19(1/2), 69-87.

Gess-Newsome, J., Southerland, S. A., Johnston, A., \& Woodbury, S. (2003). Educational reform, personal practical theories, and dissatisfaction: The anatomy of change in college science teaching. American Educational Research Journal, 40(3), 731-767. https://doi.org/10.3102/00028312040003731

Glaze-Crampes, A. L. (2020). Leveraging communities of practice as professional learning communities in science, technology, engineering, math (STEM) education. Education Sciences, 10(190), 1-8. https://doi. org/10.3390/educsci10080190

Guba, E. G. (1981). Criteria for assessing the trustworthiness of naturalistic inquiries. ECTJ, 29(2), 75. https://doi.org/10.1007/BF02766777

Hardre, P. L. (2012). Community college faculty motivation for basic research, teaching research, and professional development. Community College Journal of Research and Practice, 36(8), 539-561. https://doi. org/10.1080/10668920902973362

Luft, J. A., \& Roehrig, G. H. (2007). Capturing science teachers' epistemological beliefs: The development of the Teacher Beliefs Interview. Electronic Journal of Science Education, 11(2), 38-63.

Mattheis, A., \& Jensen, M. (2014). Fostering improved anatomy and physiology instructor pedagogy. Advances in Physiology Education, 38(4), 321329. https://doi.org/10.1152/advan.00061.2014

Miles, M. B., Huberman, A. M., \& Saldana, J. (2014). Qualitative data analysis: A methods sourcebook. Thousand Oaks, CA: Sage.

Oleson, A., \& Hora, M. T. (2014). Teaching the way they were taught? Revisiting the sources of teaching knowledge and the role of prior experience in shaping faculty teaching practices. Higher Education, 68(1), 2945. https://doi.org/10.1007/s10734-013-9678-9

Olitsky, S. (2015). facilitating changes in college teaching practices: Instructional reform, identity conflict and professional community in a K-20 partnership. Research in Science Education, 45(4), 625-646. https://doi. org/10.1007/s11165-014-9441-y

Parker, C., Morrell, C., Morrell, C., \& Chang, L. (2016). Shifting understandings of community college faculty members: Results of an equity-focused professional development experience. Journal of Faculty Development 30(3), 41-47

Posner, G. J., Strike, K. A., Hewson, P. W., \& Gertzog, W. A. (1982). Accommodation of a scientific conception: Toward a theory of conceptual change. Science Education, 66(2), 211-227.

Saka, Y., \& Keklikci, N. (2019). Exploring the interaction between science teachers' self-efficacy beliefs and pedagogical discontentment: An attempt to understand why science education reform fails. International Journal of Psychology and Educational Studies, 6(2), 1-14. https://doi. org/10.17220/ijpes.2019.02.001

Schinske, J. N., Balke, V. L., Bangera, M. G., Bonney, K. M., Brownell, S. E., Carter, R. S., ... \& Corwin, L. A. (2017). Broadening participation in biology education research: Engaging community college students and faculty. CBE-Life Sciences Education, 16(2), mr1. https://doi.org/10.1187/ cbe.16-10-0289

Schwandt, T. A., Lincoln, Y. S., \& Guba, E. G. (2007). Judging interpretations: But is it rigorous? trustworthiness and authenticity in naturalistic 
evaluation. New Directions for Evaluation, 2007(114), 11-25. https://doi org/10.1002/ev.223

Seithers, L. C., Hyson, A. R., Hull, K., \& Jensen, M. S. (2020). Community college human anatomy and physiology faculty's professional growth. Electronic Journal for Research in Science \& Mathematics Education, 24(4), 91-108.

Southerland, S. A., Sowell, S., Blanchard, M., \& Granger, E. M. (2011). Exploring the construct of pedagogical discontentment: A tool to understand science teachers' openness to reform. Research in Science Education, 41(3), 299-317. https://doi.org/10.1007/s11165 $-010-9166-5$

Twombly, S., \& Townsend, B. K. (2008). Community college faculty what we know and need to know. Community College Review, 36(1), 524. https://doi.org/10.1177/0091552108319538
Walter, E. M., Henderson, C. R., Beach, A. L., \& Williams, C. T. (2016) Introducing the Postsecondary Instructional Practices Survey (PIPS): A concise, interdisciplinary, and easy-to-score survey. CBE-Life Sciences Education, 15(4), ar53. https://doi.org/10.1187/cbe.15-09-0193

Wenger, E. (2000). Communities of practice and social learning systems. Organization, 7(2), 225-246. https://doi.org/10.1177/135050840072002

Wieman, C., \& Gilbert, S. (2014). The Teaching Practices Inventory: A new tool for characterizing college and university teaching in mathematics and science. CBE-Life Sciences Education, 13(3), 552-569. https://doi. org/10.1187/cbe.14-02-0023

Woodbury, S., \& Gess-Newsome, J. (2002). Overcoming the paradox of change without difference: A model of change in the arena of fundamental school reform. Educational Policy, 16(5), 763-782. https://doi. org/10.1177/089590402237312 